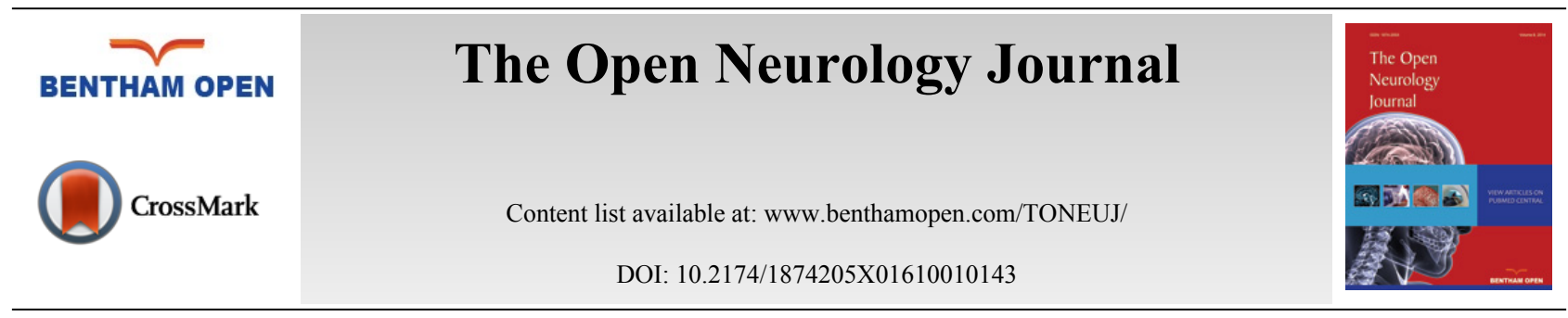

RESEARCH ARTICLE

\title{
Functional and Genomic Features of Human Genes Mutated in Neuropsychiatric Disorders
}

\author{
Diego A. Forero ${ }^{1,4, *}$, Carlos F. Prada ${ }^{2}$ and George Perry ${ }^{3}$ \\ ${ }^{1}$ Laboratory of NeuroPsychiatric Genetics, Biomedical Sciences Research Group, School of Medicine, Universidad \\ Antonio Nariño, Bogotá, Colombia \\ ${ }^{2}$ Grupo de Citogenética, Filogenia y Evolución de Poblaciones, Universidad del Tolima. Ibagué, Colombia \\ ${ }^{3}$ College of Sciences, University of Texas at San Antonio, San Antonio, Texas, USA
}

Received: June 26, 2016

Revised: September 08, 2016

Accepted: September 16, 2016

\begin{abstract}
:
Background:

In recent years, a large number of studies around the world have led to the identification of causal genes for hereditary types of common and rare neurological and psychiatric disorders.
\end{abstract}

\section{Objective:}

To explore the functional and genomic features of known human genes mutated in neuropsychiatric disorders.

\section{Methods:}

A systematic search was used to develop a comprehensive catalog of genes mutated in neuropsychiatric disorders (NPD). Functional enrichment and protein-protein interaction analyses were carried out. A false discovery rate approach was used for correction for multiple testing.

\section{Results:}

We found several functional categories that are enriched among NPD genes, such as gene ontologies, protein domains, tissue expression, signaling pathways and regulation by brain-expressed miRNAs and transcription factors. Sixty six of those NPD genes are known to be druggable. Several topographic parameters of protein-protein interaction networks and the degree of conservation between orthologous genes were identified as significant among NPD genes.

\section{Conclusion:}

These results represent one of the first analyses of enrichment of functional categories of genes known to harbor mutations for NPD. These findings could be useful for a future creation of computational tools for prioritization of novel candidate genes for NPD.

Keywords: Biological psychiatry, Brain diseases, Computational biology, Genomics, Neurological disorders, Systems biology.

\section{INTRODUCTION}

Neuropsychiatric disorders (NPD) represent a large burden on global public health, in terms of the disabilityadjusted life-years associated with them [1]. Taking into account the severity and chronicity of some of these disorders, global annual costs of NPD have been estimated at several trillion dollars [2].

\footnotetext{
* Address correspondence to this author at the Laboratory of NeuroPsychiatric Genetics, School of Medicine, Universidad Antonio Nariño, Bogotá, Colombia; Tel:+ 57313 2610427; E-mail: diego.forero@uan.edu.co
} 
For several NPD, particularly for neurological disorders, a large heritability for subtypes with Mendelian inheritance has been identified [3]. In the last years, several large efforts have been carried out to identify the causal genes for a large number of NPD [4]. Initially, classical genome-wide linkage studies, followed for fine-mapping and gene sequencing analyses, were used. Recently, genome-wide and exome sequencing studies [5] have generated a large number of causal genes for NPD [6]. Several available databases provide information for genes mutated in specific categories of NPD [7]. However, there is a lack of a global functional analysis of all genes that are known to harbor mutations for NPD. In the current work, we present a comprehensive catalog of genes mutated in neuropsychiatric disorders and we explore the genomic and functional features of those 300 genes.

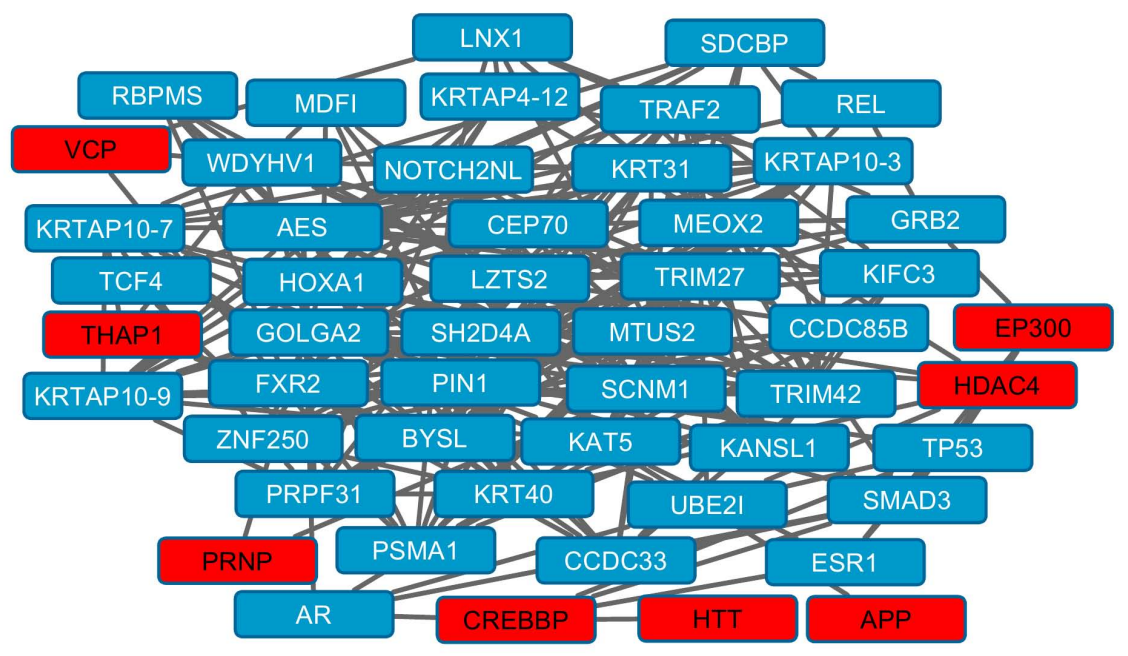

Fig. (1). Overview of Protein-Protein Interaction Networks for Genes Mutated in Neuropsychiatric Disorders (NPDs). A subnetwork of Highly Connected Proteins (> 25 connections) is shown. Proteins encoded by genes mutated in NPD and their known interacting proteins are represented in red and blue, respectively.

\section{METHODS}

Identification of genes mutated in NPD was carried out by a combination of automatic and manual search strategies of the scientific literature and associated databases. Original articles were identified and data (such as first author, gene names, disorders and PubMed identifiers -PMIDs-] were extracted and stored. HUGO Gene Nomenclature Committee [HGNC] database [8] was used for identification of official gene symbols and names. DAVID server [9] was used for conversion of HGNC IDs to Ensembl Gene IDs. Ensembl BioMart [10] was used for retrieval of chromosome, band, gene start and end, gene size, transcript count and GC\% data. The LiftOver tool of the University of California at Santa Cruz [UCSC] genome browser [11] was used to convert coordinates from hg38 to hg19 assemblies, hg19 was used because the latest available annotation for that genome version was more complete.

DAVID server (9) was used for functional clustering and enrichment analysis: Kyoto Encyclopedia of Genes and Genomes (KEGG) Pathways, Gene Expression, Chromosomal Location, Interpro domains, UCSC Transcription Factor Binding Sites [TFBS], and Gene Ontology [GO] terms. Babelomics [FatiGO] Server [12] was used for functional enrichment analysis: miRNA targets and KEGG pathways. For both programs, the option of comparing against the entire genome was chosen and a False Discovery Rate (FDR) approach was used for correction for multiple testing. A random sample of protein coding genes (from Ensembl database, $\mathrm{N}=300$ ) was generated to analyze continuous variables (gene length, GC content and transcript counts), which were compared using a Mann-Whitney U test using the Stata 11 program (those variables presented a non-normal distribution).

Protein Protein Interaction (PPI) data were retrieved from the Human Interactome Project (Center for Cancer Systems Biology, Harvard University, USA). It consolidates different datasets: HI-II-14 and Lit-BM-13 [13], HI-I-05 [14]; Venkatesan-09 [15] and Yu-11 [16]. It led to 3482 interactions for 134 NPD proteins and 619 interactor proteins. VLOOKUP option in Excel 2013 was used for generation and integration of novel tables. Cytoscape 3.1 [17] was used for analysis and visualization of PPI networks. To facilitate PPI visualization, a subnetwork of highly connected proteins ( $>25$ connections) was generated with the respective options in Cytoscape. A PPI network enrichment analysis 
was carried out with the SNOW tool [12], focusing on the following parameters: relative betweenness, connections and clustering coefficient. A list of druggable genes [18] was downloaded from the DGIdb database [19].

Sequences of the corresponding orthologous genes in Hominoids (chimpanzee, gorilla, orangutan and gibbon) were downloaded from the Ensembl database [20] and aligned using the MUSCLE alignment program [21]. Geneious software was used as a bioinformatics platform for all comparative analyses [22]. Two groups of genes were created: A group of proteins that are highly conserved between primates ( $>90 \%$ identity) and a second, less conserved group ( $<90 \%$ identity). Genes that have a unique gene structure in humans, compared with orthologues, were identified. Additionally, NPD genes that are located near or inside fragile regions of human X chromosome were recognized [23].

Table 1. Genomic analysis of 300 human genes known to be mutated in neuropsychiatric disorders.

\begin{tabular}{|c|c|c|c|c|}
\hline Category & Feature & n (\%) & $p$ value & FDR \\
\hline Chromosomal Location & Chromosome X & $45 / 294(15.3)$ & $1,0 \mathrm{E}-11 \mathrm{a}$ & $8,1 \mathrm{E}-9$ \\
\hline Gene Size & Gene Length & & $0.0000 \mathrm{~d}$ & \\
\hline Transcriptional Complexity & Transcript count & & $0.0000 \mathrm{~d}$ & \\
\hline Gene Expression (GNF_U133A) & Expression in Occipital Lobe & $88 / 294(29.9)$ & $2,9 \mathrm{E}-11 \mathrm{a}$ & $3,1 \mathrm{E}-8$ \\
\hline Gene Expression (GNF_U133A) & Expression in Prefrontal Cortex & $73 / 294(24.8)$ & $4,6 \mathrm{E}-7 \mathrm{a}$ & $4,9 \mathrm{E}-4$ \\
\hline Protein Domains (INTERPRO) & Ion Transport Domain & $14 / 294(4.8)$ & $3,8 \mathrm{E}-8 \mathrm{a}$ & $5,8 \mathrm{E}-5$ \\
\hline TF binding sites (UCSC) & SOX5 & $148 / 294(60.5)$ & $1,2 \mathrm{E}-12 \mathrm{a}$ & $1,4 \mathrm{E}-9$ \\
\hline TF binding sites (UCSC) & $\mathrm{ZIC2}$ & $108 / 294(36.7)$ & $1,7 \mathrm{E}-12 \mathrm{a}$ & $2,1 \mathrm{E}-9$ \\
\hline TF binding sites (UCSC) & PAX6 & $191 / 294(65.0)$ & $1,5 \mathrm{E}-11 \mathrm{a}$ & $1,8 \mathrm{E}-8$ \\
\hline TF binding sites (UCSC) & NF1 & $141 / 294(48.0)$ & 7,4E-10 a & $9,1 \mathrm{E}-7$ \\
\hline TF binding sites (UCSC) & POU3F2 & $189 / 294(64.3)$ & 4,4E-7 a & $5,4 \mathrm{E}-4$ \\
\hline TF binding sites (UCSC) & EN1 & $174 / 294(59.2)$ & $6,9 \mathrm{E}-7 \mathrm{a}$ & $8,5 \mathrm{E}-4$ \\
\hline miRNA targets & hsa-let-7a & $21 / 300(7.0)$ & $0.001 \mathrm{~b}$ & 0.03 \\
\hline miRNA targets & hsa-mir-92b & $18 / 300(6.0)$ & $0.001 \mathrm{~b}$ & 0.04 \\
\hline miRNA targets & hsa-let-7g & $23 / 300(7.7)$ & $0.0005 \mathrm{~b}$ & 0.02 \\
\hline
\end{tabular}

a. DAVID server

b. FatiGO server c. SNOW server

d. Mann-Whitney U test

Abbreviations: TF: Transcription Factor; FDR: False Discovery Rate.

Table 2. Functional enrichment analysis of 300 human genes known to be mutated in neuropsychiatric disorders.

\begin{tabular}{|c|c|c|c|c|}
\hline Category & Feature & n (\%) & $p$ value & FDR \\
\hline Biological Process (GO) & Nervous system development & $76 / 294(25.9)$ & $1,6 \mathrm{E}-23 \mathrm{a}$ & $2,8 \mathrm{E}-20$ \\
\hline Biological Process (GO) & Transmission of nerve impulse & $39 / 294(13.3)$ & $2,3 \mathrm{E}-18 \mathrm{a}$ & $4,1 \mathrm{E}-15$ \\
\hline Cellular Component (GO) & Neuron projection & $43 / 294(14.6)$ & $3,8 \mathrm{E}-24 \mathrm{a}$ & $5,2 \mathrm{E}-21$ \\
\hline Molecular Function (GO) & Ion channel activity & $29 / 294(9.9)$ & $2,1 \mathrm{E}-10 \mathrm{a}$ & $3,1 \mathrm{E}-7$ \\
\hline Signaling Pathways (KEGG) & Wnt signaling pathway & $8 / 300(2.7)$ & $0.0008 \mathrm{~b}$ & 0.03 \\
\hline Signaling Pathways (KEGG) & Notch signaling pathway & $5 / 300(1.7)$ & $0.0003 \mathrm{~b}$ & 0.01 \\
\hline Signaling Pathways (KEGG) & Long-term potentiation & $5 / 300(1.7)$ & $0.001 \mathrm{~b}$ & 0.04 \\
\hline Signaling Pathways (KEGG) & MAPK signaling pathway & $11 / 300(3.7)$ & $0.001 \mathrm{~b}$ & 0.03 \\
\hline Protein-Protein Interaction Networks & Relative betweenness & & $0.01 \mathrm{c}$ & \\
\hline Protein-Protein Interaction Networks & Connections & & $0.01 \mathrm{c}$ & \\
\hline Protein-Protein Interaction Networks & Clustering Coefficient & & $0.0007 \mathrm{c}$ & \\
\hline
\end{tabular}

a. DAVID server

b. FatiGO server

c. SNOW server

Abbreviations: GO: Gene Ontology; KEGG: Kyoto Encyclopedia of Genes and Genomes; MAPK: Mitogen-activated protein kinases; FDR: False Discovery Rate.

\section{RESULTS}

300 genes were identified as known to harbor mutations for NPD (Table S1). These genes belong to several functional categories, such as neurotransmitter receptors, ion channels, synaptic proteins, adhesion molecules, among other groups (Table S2). A functional enrichment analysis of these genes found several significant categories (Table 1). $15 \%$ of NPD genes are located on chromosome X and they have larger lengths and transcript counts. 
In terms of functional pathways, genes related to Wnt, Notch, MAPK signaling and long-term potentiation mechanisms were overrepresented (Table 2). Among protein domains, only the ion transport domain from InterPro was significant. In terms of regulatory mechanisms, several transcription factors (TF) known to be involved in brain physiology and three miRNAs were identified (hsa-let-7a, hsa-mir-92b, hsa-let-7g) (Table 1), with an enrichment of genes expressed in prefrontal cortex and occipital lobe. A number of significant categories from the Gene Ontology were nervous system development, transmission of nerve impulse, neuron projection and ion channel activity (Table 2 ).

Several topographic parameters of protein-protein interaction networks were significant: Relative betweenness, connections and clustering coefficient (Table 2). Fig. (1) shows an overview of protein-protein interactions for a subnetwork of highly connected proteins. Sixty six NPD genes were identified as known as druggable (Table S3).

From the analysis of conservation among orthologues of NPD genes, two main groups were identified: A group of 272 genes that are highly conserved between primates ( $>90 \%$ identity) and a second, less conserved group ( $<90 \%$ identity) with 28 genes. A multiple alignment of the second group of orthologous genes showed that the encoded proteins had from 55.1 to $90.6 \%$ identity, with a percentage of identical sites between 13.5 to $79.2 \%$ (Table S4). As an example, Fig. (S1) shows the alignment of the REEP1 orthologous genes, highlighting their low protein identity and Fig. (S2) shows the protein alignment of ARID1B, underscoring that the human protein has 429 additional amino acids at the N-terminal position (1 to 429 aminoacids) compared with orthologous genes found in Hominoids. Finally, nine NPD genes, highly conserved in primates, were found inside or adjacent to fragile regions previously reported in the human X chromosome (Table S5).

\section{DISCUSSION}

These results represent one of the first analyses of enrichment of functional categories of genes known to harbor mutations for NPD [4]. Previous studies that were focused on analyses of all genes for human diseases identified several genomic features [such as gene length] that were significant predictors [24].

In this study, we found several genomic features for NPD, such as larger gene lengths and transcript counts, location on chromosome X, presence of ion transport protein domains, expression in prefrontal cortex and regulation by several transcription factors that are known to be involved in brain function [4, 25]. As miRNAs are being identified as novel major regulators of brain function and NPD [26], it is interesting that in this study we found a possible common regulation by three miRNAs. Given the large number of features tested, a false discovery rate approach was used for correction for multiple testing.

In terms of functional analyses, we found an enrichment of categories such as gene ontologies related to neural transmission and plasticity and signaling networks linked to synaptic plasticity (such as Wnt and Notch), which have been previously postulated as underlying several NPD [27 - 29]. Of special interest, from a systems biology perspective, we found several topographic parameters of protein-protein interaction networks that were significant for NPD genes $[30,31]$. We found that 66 NPD genes are known to be druggable, a finding of relevance for development of novel therapeutic interventions [19].

We found that nine NPD genes are located inside or adjacent to fragile regions previously reported in the human X chromosome [23], with 28 NPD genes found to be less conserved among primates ( $<90 \%$ identity) and with 5 NPD genes showing a unique gene structure in humans, compared with orthologues.

Of special relevance, from a global public health perspective, is the future identification of additional causal genes for NPD, particularly in developing countries [32 - 36]. These results could be useful for the future creation of computational tools [37] that allow prioritization of novel candidate genes (including ncRNAs [26, 38]) for NPD, incorporating several of the parameters that were found in this work as significant for NPD genes.

\section{ETHICAL APPROVAL}

This article does not contain any studies with human participants or animals performed by any of the authors.

\section{SUPPLEMENTARY MATERIAL}

Supplementary material is available on the publishers Website along with the published article.

\section{CONFLICT OF INTEREST}

The authors confirm that this article content has no conflict of interest. 


\section{ACKNOWLEDGEMENTS}

This work was supported by research grants from VCTI-UAN (grant \# 2016220) and Colciencias (grant \# 823-2015). We thank Professor Jason Moore for his important suggestions.

\section{REFERENCES}

[1] Prince M, Patel V, Saxena S, et al. No health without mental health. Lancet 2007; 370(9590): 859-77. [http://dx.doi.org/10.1016/S0140-6736(07)61238-0] [PMID: 17804063]

[2] DiLuca M, Olesen J. The cost of brain diseases: a burden or a challenge? Neuron 2014; 82(6): 1205-8. [http://dx.doi.org/10.1016/j.neuron.2014.05.044] [PMID: 24945765]

[3] Zhu X, Need AC, Petrovski S, Goldstein DB. One gene, many neuropsychiatric disorders: lessons from Mendelian diseases. Nat Neurosci 2014; 17(6): 773-81.

[http://dx.doi.org/10.1038/nn.3713] [PMID: 24866043]

[4] Gratten J, Wray NR, Keller MC, Visscher PM. Large-scale genomics unveils the genetic architecture of psychiatric disorders. Nat Neurosci 2014; 17(6): 782-90. [http://dx.doi.org/10.1038/nn.3708] [PMID: 24866044]

[5] Bamshad MJ, Ng SB, Bigham AW, et al. Exome sequencing as a tool for Mendelian disease gene discovery. Nat Rev Genet 2011; 12(11): 745-55. [http://dx.doi.org/10.1038/nrg3031] [PMID: 21946919]

[6] Gratten J, Visscher PM, Mowry BJ, Wray NR. Interpreting the role of de novo protein-coding mutations in neuropsychiatric disease. Nat Genet 2013; 45(3): 234-8

[http://dx.doi.org/10.1038/ng.2555] [PMID: 23438595]

[7] Cruts M, Theuns J, Van Broeckhoven C. Locus-specific mutation databases for neurodegenerative brain diseases. Hum Mutat 2012; 33(9): 1340-4. [http://dx.doi.org/10.1002/humu.22117] [PMID: 22581678]

[8] Gray KA, Yates B, Seal RL, Wright MW, Bruford EA. Genenames.org: the HGNC resources in 2015. Nucleic Acids Res 2015; 43(Database issue): D1079-85.

[http://dx.doi.org/10.1093/nar/gku1071] [PMID: 25361968]

[9] Huang W, Sherman BT, Lempicki RA. Systematic and integrative analysis of large gene lists using DAVID bioinformatics resources. Nat Protoc 2009; 4(1): 44-57.

[http://dx.doi.org/10.1038/nprot.2008.211] [PMID: 19131956]

[10] Kinsella RJ, Kahari A, Haider S, et al. Ensembl BioMarts: a hub for data retrieval across taxonomic space Database 2011; 2011 : bar030. [http://dx.doi.org/10.1093/database/bar030] [PMID: 21785142]

[11] Rosenbloom KR, Armstrong J, Barber GP, et al. The UCSC Genome Browser database: 2015 update. Nucleic Acids Res 2015; 43(D1): D670-81. [http://dx.doi.org/10.1093/nar/gku1177] [PMID: 25428374]

[12] Medina I, Carbonell J, Pulido L, et al. Babelomics: an integrative platform for the analysis of transcriptomics, proteomics and genomic data with advanced functional profiling. Nucleic Acids Res 2010; 38(Suppl. 2): W210-3. [http://dx.doi.org/10.1093/nar/gkq388] [PMID: 20478823]

[13] Rolland T, Taşan M, Charloteaux B, et al. A proteome-scale map of the human interactome network. Cell 2014; $159(5): 1212-26$. [http://dx.doi.org/10.1016/j.cell.2014.10.050] [PMID: 25416956]

[14] Rual JF, Venkatesan K, Hao T, et al. Towards a proteome-scale map of the human protein-protein interaction network. Nature 2005; 437(7062): 1173-8.

[http://dx.doi.org/10.1038/nature04209] [PMID: 16189514]

[15] Venkatesan K, Rual JF, Vazquez A, et al. An empirical framework for binary interactome mapping. Nat Methods 2009; 6(1): 83-90. [http://dx.doi.org/10.1038/nmeth.1280] [PMID: 19060904]

[16] Yu H, Tardivo L, Tam S, et al. Next-generation sequencing to generate interactome datasets. Nat Methods 2011; 8(6): 478-80. [http://dx.doi.org/10.1038/nmeth.1597] [PMID: 21516116]

[17] Smoot ME, Ono K, Ruscheinski J, Wang PL, Ideker T. Cytoscape 2.8: new features for data integration and network visualization. Bioinformatics 2011; 27(3): 431-2.

[http://dx.doi.org/10.1093/bioinformatics/btq675] [PMID: 21149340]

[18] Russ AP, Lampel S. The druggable genome: an update. Drug Discov Today 2005; 10(23-24): 1607-10. [http://dx.doi.org/10.1016/S1359-6446(05)03666-4] [PMID: 16376820]

[19] Griffith M, Griffith OL, Coffman AC, et al. DGIdb: mining the druggable genome. Nat Methods 2013; 10(12): 1209-10. [http://dx.doi.org/10.1038/nmeth.2689] [PMID: 24122041]

[20] Cunningham F, Amode MR, Barrell D, et al. Ensembl 2015. Nucleic Acids Res 2015; 43(D1): D662-9. [http://dx.doi.org/10.1093/nar/gku1010] [PMID: 25352552] 
[21] Edgar RC. MUSCLE: multiple sequence alignment with high accuracy and high throughput. Nucleic Acids Res 2004; $32(5)$ : $1792-7$. [http://dx.doi.org/10.1093/nar/gkh340] [PMID: 15034147]

[22] Kearse M, Moir R, Wilson A, et al. Geneious Basic: an integrated and extendable desktop software platform for the organization and analysis of sequence data. Bioinformatics 2012; 28(12): 1647-9. [http://dx.doi.org/10.1093/bioinformatics/bts199] [PMID: 22543367]

[23] Prada CF, Laissue P. A high resolution map of mammalian X chromosome fragile regions assessed by large-scale comparative genomics. Mammalian genome : official journal of the International Mammalian Genome Society 2014; 25(11-12): 618-35. [http://dx.doi.org/10.1007/s00335-014-9537-8] [PMID: 25086724]

[24] Adie EA, Adams RR, Evans KL, Porteous DJ, Pickard BS. Speeding disease gene discovery by sequence based candidate prioritization. BMC Bioinformatics 2005; 6: 55. [http://dx.doi.org/10.1186/1471-2105-6-55] [PMID: 15766383]

[25] Vaquerizas JM, Kummerfeld SK, Teichmann SA, Luscombe NM. A census of human transcription factors: function, expression and evolution. Nat Rev Genet 2009; 10(4): 252-63. [http://dx.doi.org/10.1038/nrg2538] [PMID: 19274049]

[26] Forero DA, van der Ven K, Callaerts P, Del-Favero J. miRNA genes and the brain: implications for psychiatric disorders. Hum Mutat 2010; 31(11): 1195-204. [http://dx.doi.org/10.1002/humu.21344] [PMID: 20725930]

[27] Forero DA, Casadesus G, Perry G, Arboleda H. Synaptic dysfunction and oxidative stress in Alzheimers disease: emerging mechanisms. J Cell Mol Med 2006; 10(3): 796-805.

[http://dx.doi.org/10.1111/j.1582-4934.2006.tb00439.x] [PMID: 16989739]

[28] Zoghbi HY. Postnatal neurodevelopmental disorders: meeting at the synapse? Science 2003; 302(5646): 826-30. [http://dx.doi.org/10.1126/science.1089071] [PMID: 14593168]

[29] Grant SG. Synaptopathies: diseases of the synaptome. Curr Opin Neurobiol 2012; 22(3): 522-9. [http://dx.doi.org/10.1016/j.conb.2012.02.002] [PMID: 22409856]

[30] Vidal M, Cusick ME, Barabási AL. Interactome networks and human disease. Cell 2011; 144(6): 986-98. [http://dx.doi.org/10.1016/j.cell.2011.02.016] [PMID: 21414488]

[31] Grennan KS, Chen C, Gershon ES, Liu C. Molecular network analysis enhances understanding of the biology of mental disorders. BioEssays : news and reviews in molecular, cellular and developmental biology 2014; 36(6): 606-16. [http://dx.doi.org/10.1002/bies.201300147] [PMID: 24733456]

[32] Forero DA, Vélez-van-Meerbeke A, Deshpande SN, Nicolini H, Perry G. Neuropsychiatric genetics in developing countries: Current challenges. World J Psychiatry 2014; 4(4): 69-71. [http://dx.doi.org/10.5498/wjp.v4.i4.69] [PMID: 25540721]

[33] Hernández HG, Mahecha MF, Mejía A, Arboleda H, Forero DA. Global long interspersed nuclear element 1 DNA methylation in a Colombian sample of patients with late-onset Alzheimers disease. Am J Alzheimers Dis Other Demen 2014; 29(1): 50-3. [http://dx.doi.org/10.1177/1533317513505132] [PMID: 24164934]

[34] Ojeda DA, Niño CL, López-León S, Camargo A, Adan A, Forero DA. A functional polymorphism in the promoter region of MAOA gene is associated with daytime sleepiness in healthy subjects. J Neurol Sci 2014; 337(1-2): 176-9. [http://dx.doi.org/10.1016/j.jns.2013.12.005] [PMID: 24360188]

[35] Ojeda DA, Perea CS, Suarez A, et al. Common functional polymorphisms in SLC6A4 and COMT genes are associated with circadian phenotypes in a South American sample. Neurological sciences : official journal of the Italian Neurological Society and of the Italian Society of Clinical Neurophysiology 2014; 35(1): 41-7. [http://dx.doi.org/10.1007/s10072-013-1466-x] [PMID: 23728717]

[36] Gálvez JM, Forero DA, Fonseca DJ, Mateus HE, Talero-Gutierrez C, Velez-van-Meerbeke A. Evidence of association between SNAP25 gene and attention deficit hyperactivity disorder in a Latin American sample. Atten Defic Hyperact Disord 2014; 6(1): 19-23. [http://dx.doi.org/10.1007/s12402-013-0123-9] [PMID: 24362847]

[37] Moreau Y, Tranchevent LC. Computational tools for prioritizing candidate genes: boosting disease gene discovery. Nat Rev Genet 2012; 13(8): 523-36. [http://dx.doi.org/10.1038/nrg3253] [PMID: 22751426]

[38] Strazisar M, Cammaerts S, van der Ven K, et al. MIR137 variants identified in psychiatric patients affect synaptogenesis and neuronal transmission gene sets. Mol Psychiatry 2015; 20(4): 472-81. [http://dx.doi.org/10.1038/mp.2014.53] [PMID: 24888363]

(C) Forero et al.; Licensee Bentham Open

This is an open access article licensed under the terms of the Creative Commons Attribution-Non-Commercial 4.0 International Public License (CC BY-NC 4.0) (https://creativecommons.org/licenses/by-nc/4.0/legalcode), which permits unrestricted, non-commercial use, distribution and reproduction in any medium, provided the work is properly cited. 